\title{
ASSESSMENT OF RESIN -CERAMIC BOND STRENGTH UNDER VARIOUS PH CONDITIONS FOR DIFFERENT CERAMIC MATERIALS SUBJECTED TO TWO SURFACE TREATMENT PROTOCOLS
}

\author{
Reham Elbasty* and Maha Taymour**
}

\begin{abstract}
Statement of the problem: The 2 step ceramic surface treatment " $\mathrm{HF}$ acid etching followed by silane application" has been used for years to secure an efficient bond between ceramics and resin cements, however the urge for simplification and making the bonding procedure less technique sensitive have pushed the dentists to shift to one step ceramic surface treatment "self etch ceramic primer". Although studies proved their reliability, till now there is no data available on their effect on bond stability in different $\mathrm{pH}$ conditions
\end{abstract}

Purpose: The aim of the current study was to evaluate microshear bond strength between resin and different ceramic materials (e.max, VITA ENAMIC and VITA SUPPRINITY) preatreated with two different protocols ( 2 step and 1 step) after being subjected to various $\mathrm{pH}$ storage media

Materials and Methods: A total of ninety ceramic discs were fabricated in this study from CAD/ CAM blocks. The discs were divided into three groups according to ceramic material as follows; Group 1: Thirty discs constructed from lithium disilicate glass ceramic (e.max CAD), Group 2: Thirty discs constructed from polymer infiltrated ceramic- network material (VITA ENAMIC) and Group 3: Thirty discs constructed from Zirconia-lithium silicate glass-ceramic materials (VITA SUPRINITY). Each of the previous groups were further subdivided into two equal subgroups according to the surface treatment protocol used as follows; Subgroup 1: fifteen discs were treated with 2 step bonding protocol (etched with hydrofluoric acid followed by silane application) and Subgroup 2: fifteen discs were treated with 1 step application of self etching primer (Monobond etch and prime). The two subgroups were again equally divided ( 5 each) and assigned to one of the three storage solutions with different $\mathrm{pHs}$ : acidic, neutral and alkaline media.Ceramic discs were obtained by sectioning the CAD/CAM blocks using Isomat 1000 followed by crystallization of the e.max and VITA SUPPRINITY discs. For first subgroup, the ceramic discs were subjected to two step surface treatment protocol consisting of hydroflouric acid etching, rinsing followed by silane application. While the second subgroup was subjected to surface treament using one

* Lecturer Fixed Prosthodontic Department, Faculty of Dentistry. Cairo University.

**Associate Professor Fixed Prosthodontic Department, Faculty of Dentistry. Cairo University. 
step monobond etch and prime protocol. For both subgroups,each ceramic substrate was then prepared to receive 5 resin microtubules. Five samples of each ceramic resin assembly subgroup was then randomly selected and designated in one of the following storage media for a period of seven days:1) Cola solution representing acidic medium having $\mathrm{pH}$ value of 2.5. 2) Distilled water representing neutral medium having $\mathrm{pH}$ value of 73 ) Licorice solution representing alkaline medium having $\mathrm{pH}$ value of 8.4. At the end of the storage period,micro shear bond strength test was performed to debond the specimens in a universal testing machine (Model 3345; Instron Industrial Products, Norwood, MA, USA) with a crosshead speed of $0.5 \mathrm{~mm} / \mathrm{s}$. The maximum load at failure was recorded in Newtons (N) unit and was divided over the bonded area (mm2) to convert to MPa unit. Data was then collected, tabulated and statistically analyzed.

Results: With acidic pH: in e.max CAD and VITAENAMIC groups; it was found that two steps surface treatment approach recorded statistically significant higher mean microshear bond strength value than one step approach as proven by paired t-test $(\mathrm{P}<0.05)$, while for VITA SUPRINITY group; it was found that two steps surface treatment approach recorded statistically non-significant higher mean microshear bond strength value than one step approach as demonstrated by paired t-test $(\mathrm{P}=0.1945>0.05)$. With neutral pH: in e.max CAD and VITA ENAMIC groups; it was found that two steps surface treatment approach recorded statistically non significant higher mean microshear bond strength value than one step approach as proven by paired t-test ( $>0.05)$, while for VITA SUPRINITY group; it was found that two steps surface treatment approach recorded statistically significant higher mean microshear bond strength value than one step approach as demonstrated by paired t-test $(\mathrm{P}=0.03<0.05)$ With alkaline $\mathrm{pH}$ : : in e.max CAD and VITA ENAMIC groups; it was found that two steps surface treatment approach recorded statistically significant higher mean microshear bond strength value than one step approach as proven by paired t-test $(\mathrm{P}<0.05)$, while for VITA SUPRINITY group; it was found that two steps surface treatment approach recorded statistically non-significant higher mean microshear bond strength value than one step approach as demonstrated by paired t-test $(\mathrm{P}=0.2121>0.05)$

Conclusions: Within the limitations of this study, the following conclusions and clinical recommendations could be advised:1) Although microshear bond strength of the two step etch and prime surface treatment protocol was significantly higher than that of one step self-etching ceramic primer protocol, however the values for all tested materials under various $\mathrm{Ph}$ conditions were nearly within a clinically acceptable range, thus it could be suggested that self etching primers can be safely used without affecting clinical performance of the restorations. 2) In patients subjected to predominately acidic or alkaline oral $\mathrm{pH}$ environments, both surface treatment protocols can be safely used when VITA SUPPRINITY restorations are indicated, however when VITA ENAMIC or e.max CAD are used, it is recommended to use the two step surface treatment protocol to ensure more stable bond strength 3) In patients having a neutral balanced oral $\mathrm{pH}$ environment, both surface treatment protocols can be safely used when VITA ENAMIC or e.max CAD restorations are used, however when VITA SUPPRINITY is recommended, it is advisable to use the two step surface treatment protocol to yield better ceramic resin bond durability. 4) Generally speaking, VITA ENAMIC restorations combined with one step self etching primer are not recommended for patients having acidic $\mathrm{pH}$ oral media as it yielded the lowest bond strength values between all subgroups 


\section{INTRODUCTION}

All-ceramic restorations success depends mainly on efficient bond establishment between ceramic material and underlying dental tissues especially for conservative restoration designs as endocrowns and laminate veneers ${ }^{[1]}$. The production of stable bond relies on thorough recognition and analysis of the ceramic microstructure together with choosing the appropriate surface treatment protocol and adhesive resin cement. The prime purpose of ceramic pretreatment is generating surface microirregularities followed by ceramic primer application that promotes bonding to a more hydrophobic adhesive ${ }^{[2,3]}$. The ceramic surface pretreatment protocol differs according to the material; whilst feldspathic glass ceramics and leucite-reinforced glass ceramics require etching with 5-10\% hydrofluoric acid for 60 seconds, lithium disilicate glass ceramics require only 20 seconds where the acid reacts with the silica based glass matrix forming hexafluorosilicates. The glassy phase is then selectively removed exposing the crystalline structure. Hence, ceramic surface becomes rough, creating the desired micromechanical retention of the surface [4]. The etched surface also aids in increasing surface energy essential for combining with the subsequently applied organo-silane primer ${ }^{[5]}$. Whereas airborne-particle abrasion surface pretreatment is recommended for zirconia, alumina based ceramics and composite resins ${ }^{[6]}$. As for the novel hybrid ceramics, surface pretreatment varies from one type to the other, as some require hydrofluoric acid etching while others require micro-abrasion depending on their microstructure and manufacturing method ${ }^{[7,8]}$.

Silanization of the surface treated ceramics then follows as it is considered a standard protocol [9]. Silanes is formed of inorganic- organic hybrid compounds containing one or more silicon atoms (Si) directly bonded to carbon $(\mathrm{C})$ atoms. They are able to promote chemical bond between organic and inorganic compounds available in the resin and ceramic surfaces through covalent siloxane bonds ${ }^{[10]}$. Besides, silanes facilitate ceramic surface wetting, increase surface free energy and promotes the resultant adhesion strength ${ }^{[11]}$.

Nowadays, optimal ceramic surface treatment protocol achieving the best clinically resin cement bonding became an important issue for research. Many studies have figured out that hydrofluoric acid etching is the gold standard for glass ceramics treatment ${ }^{(9)}$. However, health hazards and toxicity of HF acid became a well documented issue arising clinical concern ${ }^{[12]}$. Moreover, issues about possible detrimental hydrofluoric acid effects on ceramic strength have been investigated ${ }^{[13]}$. Thus, alternative methods for ceramics pretreatment have been suggested ${ }^{[14]}$.

A single component ceramic primer has recently invaded the dental field known as self-etching ceramic primer (Monobond Etch \& Prime, Ivoclar Vivadent, Schaan, Liechtenstein) as an alternative to routine approach of using hydrofluoric acid etching step followed by application of silane coupling agent. The primer contains polyfluoride for etching and trimethoxypropylmethacrylate for silanization. The innovative technique intends to eliminate the toxic risk of using the hydrofluoric acid as a separate step. Besides, the time required and technique senstivity of ceramic etching is reduced compared to conventional methods. ${ }^{(15)}$

Irrespective to the surface treatment or adhesive protocols, bond strength stability of ceramic- resin complex has been challenged as there are previous studies figuring out a decrease in bond strength by half or one-third after storage in humid environment subjected to $\mathrm{pH}$ and thermal fluctuations ${ }^{(16-20)}$. Thus, it has been proposed that for clinically relevant bond strength evaluation for different ceramic - resin combinations, it is essential to simulate possible intraoral conditions such as the saliva and $\mathrm{pH}$ that might significantly affect the adhesive interface characteristics ${ }^{(21)}$ 
Previous studies have figured out the effect of different oral ph media on the corrosion rate of dental ceramics. ${ }^{(22-29)}$ Acidic liquids such as soda beverages (pH 2.525-4.038 for common brands) ${ }^{(30)}$ and fruit juices ( $\mathrm{pH} 2.0-5.50)$ as well as alkaline media, such as lima beans or soy beans ( $\mathrm{pH} 12)$, spinach (pH 8.3), and antacids ( $\mathrm{pH} \mathrm{10-14),} \mathrm{can} \mathrm{also} \mathrm{affect}$ the surface characteristics, chemical durability and fracture strength of ceramics as concluded by earlier researchers ${ }^{(31-34)}$ However the effect of $\mathrm{pH}$ media on resin ceramic bond strength stability has not been thoroughly investigated.

Accordingly, the present study was conducted to examine microshear bond strength between adhesive resin and different ceramic materials (Lithium disilicate, PICN and ZLS) preatreated with two different protocols ;2 step (etching followed by priming) and 1 step (self etching priming) after being subjected to different $\mathrm{pH}$ conditions (acidic, neutral and alkaline).The null hypothesis was that there would be no significant difference in bond strength between both ceramic pretreatments for the different ceramic materials under various $\mathrm{pH}$ conditions

\section{MATERIALS AND METHODS}

A total of ninety ceramic discs were fabricated in this study from CAD/CAM blocks. The discs were divided into three groups according to ceramic material as follows; Group 1: Thirty discs constructed from lithium disilicate glass ceramic (e.max CAD), Group 2: Thirty discs constructed from polymer infiltrated ceramic- network material (VITA ENAMIC) and Group 3: Thirty discs constructed from Zirconia-lithium silicate glassceramic materials (VITA SUPRINITY). Each of the previous groups were further subdivided into two equal subgroups according to the surface treatment protocol used as follows; Subgroup 1: fifteen discs were treated with 2 step bonding protocol (etched with hydrofluoric acid followed by silane application) and Subgroup 2: fifteen discs were treated with 1 step application of self etching primer (Monobond etch and prime). The two subgroups were again equally divided (5 each) and assigned to one of the three storage solutions with different pHs : acidic, neutral and alkaline media as shown in figure 1

\section{Preparation of the ceramic specimens}

The ceramic discs were sectioned from IPS e.max CAD blocks (Ivoclar Vivadent, Schaan, Liechtenstein), VITA ENAMIC blocks (Vita Zahnfabrik, Bad Sackingen, Germany) and VITA SUPRINITY blocks (Vita Zahnfabrik, Bad Sackingen, Germany) under copious water irrigation with a precision cutting machine Isomet 1000 (Buehler,Lake Bluff, USA). The obtained sectioned samples had thickness of $2 \mathrm{~mm}$. Thorough

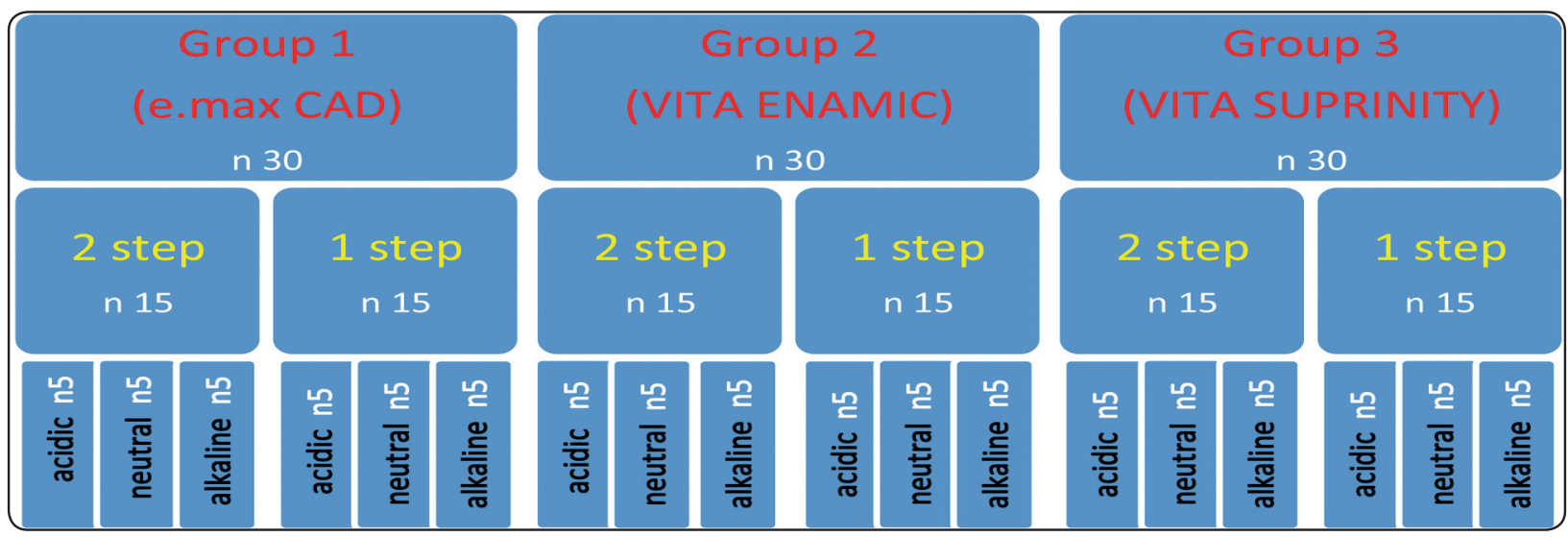

Fig. (1) Flow chart representing samples' grouping 
inspection of the samples was then done using magnifying lens for any surface defects. A digital caliper was also used to check thickness uniformity at the middle and margins of each disc. Ultrasonic cleaning bath was then done for sectioned samples for 15 minutes.

For the e.max CAD and VITA SUPPRINITY, final crystallization was then preformed to attain full strength properties of the material following the firing program recommended by the manufacturer for each material.

\section{Surface treatment of the samples:}

Each group of the tested ceramic materials was randomly divided into two equal subgroups $(n=15)$ and assigned to one of the following surface treatment protocols:

1) Two step treatment consisting of an etching step with $4.8 \%$ hydrofluoric acid (IPS Ceramic Etching gel, Ivoclar Vivadent. Schaan, Liechtenstein) for 20 seconds for e.max CAD and VITA SUPPRINITY whilst VITA ENAMIC was etched for 60 seconds. The acid was then thoroughly rinsed under running water for 20 seconds and then dried for 10 seconds with oil free air. Then a second step of silane-coupling agent (RelyXTM Cermic Primer. 3M ESPE, USA) application was done by microbrush which was allowed to dry for 1 minute. Afterwards, the excess was spread with an air stream to ensure the solvent evaporation.

2) One step treatment by self etching primer (Monobond Etch \& Prime, Ivoclar Vivadent Schaan, Liechtenstein), which was applied using a microbrush on the ceramic substrate. Subsequently, it was agitated into the surface for 20 seconds, allowed to react for additional 40 seconds. Finally, it was thoroughly rinsed off with an air/water spray jet for 20 seconds and dried for 10 seconds with oil-free air.

\section{Resin application on treated ceramic substrate}

The specimen preparation methodology for the microshear bond strength followed a study that was developed by Shimada ${ }^{(35)}$

For both groups, Adhesive resin (Single Bond 2,3M ESPE, USA) was then applied using a brush on the ceramic areas designated to receive the resin microtubulues.

Each ceramic substrate surface received 5 resin microtubules. A transparent polyvinyl tube with inner diameter $0.9 \mathrm{~mm}$ was cut to form small microtubules of $1 \mathrm{~mm}$ height. Each micro-tubule was adjusted over the bonded ceramic surface with a $6 \mathrm{~mm}$ minimum distance between them to allow their insertion and subsequent removal. The previously applied adhesive was then lightly air thinned and cured for 20 seconds using light emitting diode curing unit of high intensity 1500 $\mathrm{mW} / \mathrm{cm} 2$. The polyvinyl tubes was then filled with flowable nanohybrid composite resin (Filtek TM Supreme Ultra Flowable, 3M ESPE, USA) that was light cured for 40 seconds. The bonded specimens were stored in distilled water at $37^{\circ} \mathrm{C}$ for $24 \mathrm{~h}$. The resin cylinders were then exposed by sectioning the polyvinyl tube. The resin cylinders were then checked for completeness and absence of bubbles or excess material at the interface.

\section{Storage of samples in different $\mathrm{Ph}$ media}

Five samples of each ceramic resin assembly subgroup was randomly selected and designated in one of the following storage media for a period of seven days:

1) (5 ml) Cola solution representing acidic medium having $\mathrm{pH}$ value of 2.5

2) $(5 \mathrm{ml})$ Distilled water representing neutral medium having $\mathrm{pH}$ value of 7

3) (5 ml) Licorice solution representing alkaline medium having $\mathrm{pH}$ value of 8.4 
The $\mathrm{pH}$ value of the different storage media was measured by a digital waterproof $\mathrm{pH}$ meter (Adwa AD 11, Romania) as shown in figure 2. Specimens were immersed individually in closed vials containing $5 \mathrm{ml}$ of each medium and stored at $37^{\circ}$ in an incubator (CBM.TORRE PICENARDI(CR), Model 431/V, Italy). The solutions were freshened daily to avoid yeast or bacterial contamination and stirred twice daily to reduce the precipitation of particles. By the end of the immersion period, specimens were rinsed with distilled water and wiped with gauze

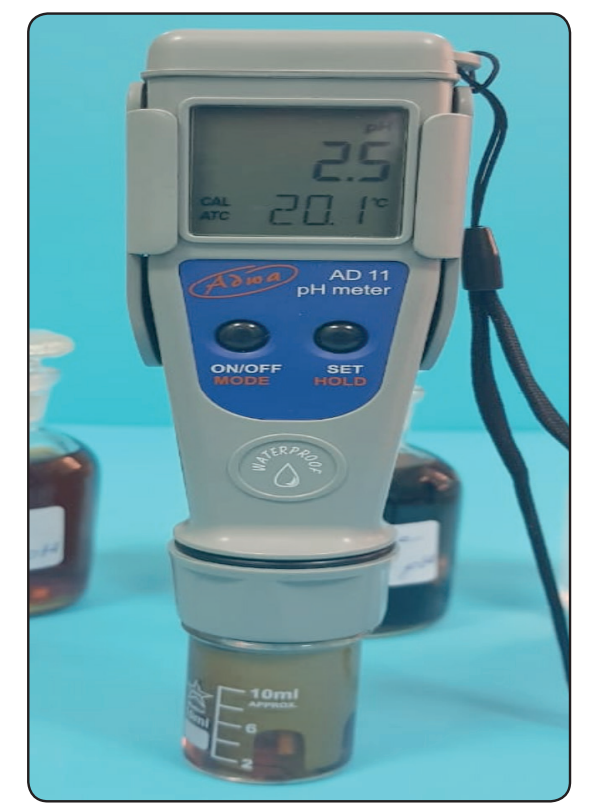

Fig. (2) Digital $\mathrm{pH}$ meter verifying $\mathrm{pH}$ of cola solution

\section{Micro-shear bond Strength testing}

The test was performed using Bluehill Lite Software from Instron ${ }^{\circledR}$. Each ceramic resin assembly was mounted into central hole of special designed sample holder jig secured with tightening screws to the lower fixed compartment of a material testing machine (Model 3345; Instron Industrial Products, Norwood, MA, USA) with a load cell of $5 \mathrm{kN}$ and data were recorded using computer software (Instron ${ }^{\circledR}$ Bluehill Lite Software). A loop prepared from an orthodontic wire $(0.014$ " in diameter) was wrapped around the bonded microcylinder assembly as close as possible to the base of the microcylinder and aligned with the loading axis of the upper movable compartment of the testing machine. A shearing load with tensile mode of force was applied via universal testing machine at a crosshead speed of $0.5 \mathrm{~mm} / \mathrm{min}$. The load required to debonding was recorded in Newton.

\section{Micro-Shear bond strength calculation}

The load at failure was divided by bonding area to express the bond strength in MPa : $\boldsymbol{\tau}=\mathbf{P} / \boldsymbol{\pi} \mathbf{r}^{2}$ where ; $\boldsymbol{\tau}=\mu$-shear bond strength (in MPa), $\mathbf{P}=$ load at failure (in $\mathrm{N}$ ), $\boldsymbol{\pi}=3.14$ and $\mathbf{r}=$ radius of microcylinder (in $\mathrm{mm}$ )

The collected data were then tabulated and statistically analyzed.

Data analysis was performed in several steps. Initially, descriptive statistics for each group results. Three-way ANOVA was done to detect effect of each variable (material, surface treatment approaches\& $\mathrm{pH}$ solutions). One way ANOVA followed by pairwise Tukey's post-hoc tests were performed to detect significance between material groups and $\mathrm{pH}$ solutions. Paired t-test was performed between surface treatment approaches. Histograms and charts were created using Microsoft excel. Statistical analysis was performed using Graph Pad Instat (Graph Pad, Inc.) software for windows. P values $\leq 0.05$ are considered to be statistically significant in all tests.

\section{RESULTS}

\section{Microshear bond strength test results:}

The mean values and standard deviation of $\mu$-shear bond strength test results for all materials as function of both surface treatment approaches and $\mathrm{pH}$ solutions are summarized in table (1) and graphically drawn in figure (3). 
TABLE (1) Microshear bond strength results (Mean values \pm SDs) of both surface treatment approaches for all materials as function of $\mathrm{pH}$ solutions

\begin{tabular}{|c|c|c|c|c|}
\hline \multirow{2}{*}{ pH solution } & \multirow{2}{*}{ Material group } & \multicolumn{2}{|c|}{ Surface Treatment approaches } & \multirow[b]{2}{*}{ Pvalue } \\
\hline & & One step & Two steps & \\
\hline \multirow{3}{*}{ Acidic } & e.max $C A D$ & $10.13^{\mathrm{a}} \pm 3.8$ & $15.31^{\mathrm{a}} \pm 4.8$ & $0.02 *$ \\
\hline & VITA ENAMIC & $9.12^{\mathrm{a}} \pm 2.5$ & $13.08^{\mathrm{a}} \pm 5.03$ & $0.05 *$ \\
\hline & VITA SUPPRINITY & $12.59^{\mathrm{a}} \pm 0.18$ & $15.07^{\mathrm{a}} \pm 4.5$ & $0.1945 \mathrm{~ns}$ \\
\hline \multirow{3}{*}{ Neutral } & e.max $C A D$ & $11.08^{\mathrm{a}} \pm 4.3$ & $15.39^{\mathrm{a}} \pm 4.9$ & $0.1563 \mathrm{~ns}$ \\
\hline & VITA ENAMIC & $11.01^{\mathrm{a}} \pm 0.51$ & $13.78^{\mathrm{a}} \pm 5.2$ & $0.1288 \mathrm{~ns}$ \\
\hline & VITA SUPPRINITY & $11.69^{\mathrm{a}} \pm 0.2$ & $20.87^{\mathrm{a}} \pm 6.7$ & $0.03 *$ \\
\hline \multirow{3}{*}{ Alkaline } & e.max $C A D$ & $14.24^{\mathrm{a}} \pm 5.62$ & $29.84^{\mathrm{a}} \pm 10.8$ & $0.03 *$ \\
\hline & VITA ENAMIC & $10.96^{\mathrm{a}} \pm 0.61$ & $20.43^{\mathrm{a}} \pm 5.1$ & $0.017 *$ \\
\hline & VITA SUPPRINITY & $17.11^{\mathrm{a}} \pm 6.1$ & $20.11^{\mathrm{a}} \pm 2.9$ & $0.2121 \mathrm{~ns}$ \\
\hline
\end{tabular}

Different letters in the same column indicating statistically significant difference $(p<0.05)^{*} ;$ significant $(p<0.05)$ ns; non-significant ( $p>0.05)$

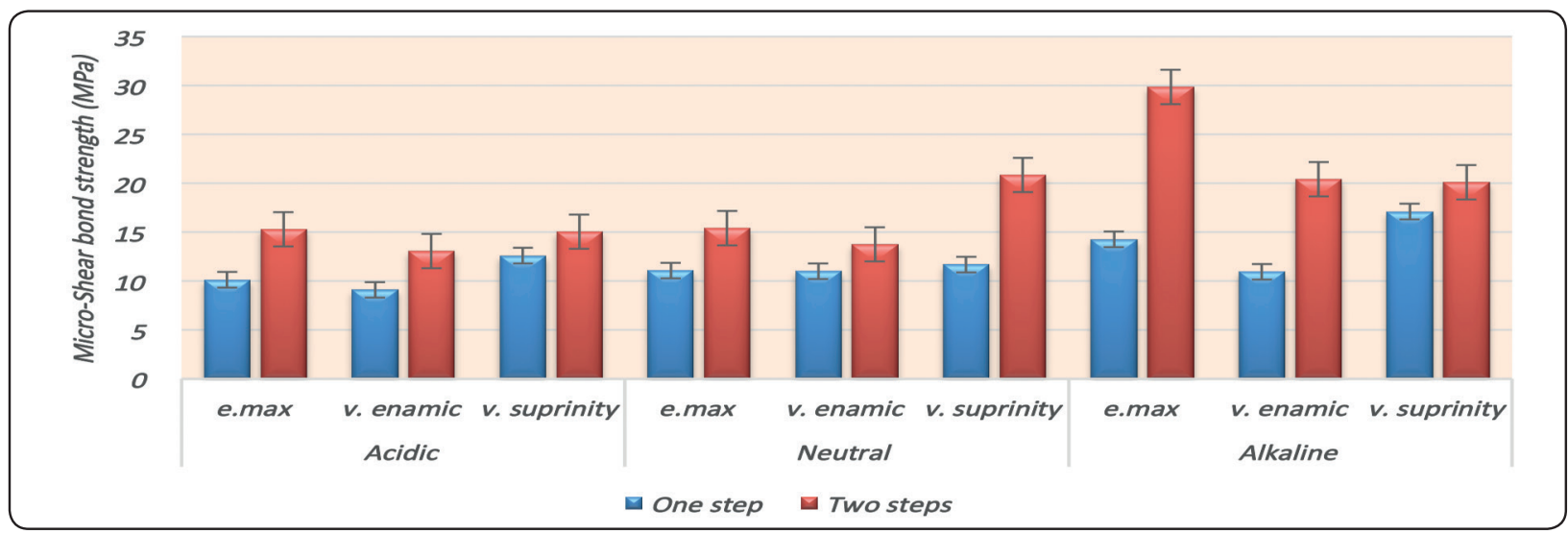

Fig. (3) : Column chart of the mean values of microshear bond strength (MPa) for the two surface treatment approaches of all materials as function of $\mathrm{pH}$ solutions

\section{Effect of material on microshear bond strength}

Regardless to surface treatment approach or $\mathrm{pH}$ solutions, there was non-significant difference between the three tested ceramic material as demonstrated by three-way ANOVA test $(\mathrm{F}=1.9, \mathrm{P}=$ $0.1496>0.05$ )

\section{Effect of surface treatment approach on micros- hear bond strength}

Irrespective of material or $\mathrm{pH}$ solutions, there was significant difference between both surface treatment approach as proven by three-way ANOVA test $(\mathrm{F}=4.2, \mathrm{P}=0.003<0.05)$ where $\boldsymbol{t w o}$ steps approach showed statistically significant higher microshear bond strength value than one step approach

\section{Effect of pH solutions on microshear bond strength}

Regardless to material or surface treatment approach, there was significant difference between $\mathrm{pH}$ solutions as verified by three-way ANOVA test $(\mathrm{F}=6.6, \mathrm{P}=0.002<0.05)$ where alkaline medium showed statistically significant higher microshear 
bond strength value than neutral and acidic media. Pair-wise Turkey's post-hoc showed non-significant $(\mathrm{P}>0.05)$ difference between neutral and acidic media

\section{One step versus two steps surface treatment protocol}

With acidic pH: In e.max CAD and VITA ENAMIC groups; it was found that two steps surface treatment approach recorded statistically significant higher mean microshear bond strength value than one step approach as proven by paired t-test $(\mathrm{P}<0.05)$, while for VITA SUPRINITY group; it was found that two steps surface treatment approach recorded statistically non-significant higher mean microshear bond strength value than one step approach as demonstrated by paired t-test $(\mathrm{P}=0.1945>0.05)$

With neutral pH: In e.max CAD and VITA ENAMIC groups; it was found that two steps surface treatment approach recorded statistically non significant higher mean microshear bond strength value than one step approach as proven by paired t-test ( $\mathrm{P}>0.05)$, while for VITA SUPRINITY group; it was found that two steps surface treatment approach recorded statistically significant higher mean microshear bond strength value than one step approach as demonstrated by paired t-test $(\mathrm{P}=$ $0.03<0.05$ )

With alkaline pH: In e.max CAD and VITA ENAMIC groups; it was found that two steps surface treatment approach recorded statistically significant higher mean microshear bond strength value than one step approach as proven by paired t-test $(\mathrm{P}<0.05)$, while for VITA SUPRINITY group; it was found that two steps surface treatment approach recorded statistically non-significant higher mean microshear bond strength value than one step approach as demonstrated by paired t-test $(\mathrm{P}=0.2121>0.05)$

\section{DISCUSSION}

Simplification of the adhesive protocols and decreasing technique senstivity of the bonding procedure is a prime target of novel dental introductions. One of these innovations was the introduction of one-step self-etching ceramic primer (Monobond® etch and prime, Ivoclar Vivadent, AG) as the first of its kind to the market. It offers a hydrofluoric acid-free etchant and primer monomers applied only in one step ${ }^{(36)}$.

However, for recent materials to be accepted, they should be thoroughly investigated through both laboratory and clinical studies under different situations.

Although hydrofluoric acid etching of different types of ceramics followed by silane application has been considered as golden standard for surface treatment of those ceramics and proved to achieve superior bond strengths with the subsequently applied adhesives ${ }^{(6)}$. However, other aspects to be considered are that $\mathrm{HF}$ acid has the risk to debilitate the mechanical properties of ceramics ${ }^{[37-40]}$, Besides, cases reporting soft tissue and bone necrosis over prolonged exposure to hydroflouric acid have been published ${ }^{[41]}$. This made the introduction of the new category of self etching primers a very promising alternative.

Until now, few studies have investigated the bond strength of self etching primers and revealed encouraging results ${ }^{[42-45]}$. However, the available data regarding the effect of storage in different $\mathrm{pH}$ solutions on resin ceramic bond strength after subjecting the ceramics surface to treatment by monobond etch and prime treatment has not been tested yet.

Thus, the aim of this study was to investigate the microshear bond strength between adhesive resin and three different groups of most commonly used ceramic materials (Lithium disilicate, PICN and ZLS) preatreated with two different protocols ;2 
step (etching followed by priming) and 1 step (self etching primer) after being subjected to different $\mathrm{pH}$ conditions (acidic, neutral and alkaline).

The physical and chemical characteristics of the oral cavity affects the properties and performance of various restorative materials. ${ }^{(46,47)}$ An important factor that should be considered during evaluation of dental restorations is the oral $\mathrm{pH}$. However, the effect of $\mathrm{pH}$ media variation on the performance of dental restorations is not well established. This makes it very beneficial to introduce the various $\mathrm{pH}$ conditions that might be present in the oral cavity in the methodology used for assesment of dental ceramics in order to clinicaly simulate the oral conditions.

The $\mathrm{Ph}$ values chosen in this study represents different conditions present in the oral cavity namely (acidic, neutral, alkaline). The acidic oral ph was found to be more common in heavy citrus fruit and carbonated beverages consumers, in patients suffering from chronic medical problems such as chronic periodontitis, chronic gastric regurgitation and chronic renal failure ${ }^{(48)}$. While alkaline oral ph was more prevalent in vegetarians, individuals having alkaline based diet, patients using frequent antacids as well as populations having chronic generalized gingivitis ${ }^{(49)}$. The neutral $\mathrm{pH}$ that was represented by distilled water was chosen as a control medium to simulate normal oral conditions.

A period of 1 week was chosen for storage of samples as the total study period. This should be equivalent to about six months of clinical ageing. ${ }^{(50,51)}$ which can give a clue about short term ceramic resin bond durability.Further studies are thus recommended to assess the effect of longer storage periods.

The methodolgy of evaluation proposed in this study was the microshear bond strength that followed the protocol introduced by Shimada et $\mathrm{al}^{(35)}$. This type of testing offers multiple advantages as it uses small cross sectional specimens which avoids heterogeneous stress distribution and cohesive failures that are common with large transverse specimen diameter. Besides, several specimens could be obtained from one sample, thus offering a time saving and cheaper solution compared to other microadhesion tests as microtensile one where the specimen need to be cut into rods after the adhesive procedure which might lead to the microcracks formation and propagation in the early stage of the test. $^{(52-54)}$.

According to the results of the present study, the null hypothesis expecting that there would be no significant difference in bond strength between both ceramic pretreatments for the different ceramic materials under various $\mathrm{pH}$ conditions was partially rejected as there was significant difference in bond strength between both treatment protocols under different storage media.

Results of the mean bond strength values for all groups and subgroups nearly fell in the value limit of 10-13 MPa which was suggested by Thurmond as the minimum for acceptable clinical bonding ${ }^{(55)}$

Regarding the effect of ceramic surface treatment protocol on the mean microshear bond strength irrespective of material or $\mathrm{pH}$ solutions, results revealed that the two steps approach had statistically significant higher value than one step approach. This could be mainly attributed to the presence of ammonium polyflouride acid in the monobond etch and prime which is a weak acid salt of hydrofluoric acid in contrast to the two step surface treatment protocol which utilizes a stronger 5\% hydrofluoric acid as an etchant.It was well documented by earlier studies that the number, width and depth of the microporosities is directly related to the concentration of acid and duration of etching.The use of weaker acid or shorter etching time results in an underetched surface which in turn reduces bond strength ${ }^{(56)}$. Under etching partially etches the glassy matrix creating shallower porosities which may impede complete penetration of the subsequently applied 
viscous resinous material ${ }^{(57)}$ Previous studies also demonstrated positive correlation between ceramic surface area, roughness and wettability which are important parameters affecting bond strength with concentration of acid and etching duration ${ }^{(56,58,59)} \mathrm{A}$ study conducted by Asiri et al in $2018^{\left({ }^{(60)}\right.}$ showed that ceramic specimens treated with two step protocol had higher roughness values and bond strength than that treated with one step self etching primers. Another study was carried by Sherer et al in $2018^{(61)}$ examining lithium disilicate ceramic surfaces treated with one step and two step conditioning methods using scanning electron microscope. This study showed that etching patterns achieved with Monobond etch and prime was superficial when compared with hydrofluoric acid application. This finding also supports results of the present study. Another explanation of our results is that when the manufacturers protocol was followed during application of Monobond etch and prime, it was thoroughly rinsed using air water spray after it was agitated for 20 seconds and left to react for additional 40 seconds. This might cause partial washing of the silane coupling agent in contrast to the two step protocol where the silane coupling agent was only air thinned. Our results regarding effect of etching protocols on the bond strength were in accordance with earlier studies ${ }^{(44,60)}$ However, it was not consistent with previous study conducted by Siqueira et al who found no significance difference between both treatment protocols. Reasons for this inconsistency might be related to different sample size and adhesive systems. ${ }^{(62)}$

When discussing the effect of $\mathrm{pH}$ solutions on microshear bond strength regardless to material or surface treatment approach, there was significant difference between $\mathrm{pH}$ solutions where alkaline medium showed significant higher microshear bond strength value than neutral and acidic media. It is well recognized from previous studies that immersion in aqueous media leads to hydrolytic degradation of silane promoted adhesive interfaces.
This phenomena is caused by hydrolytic breakage of siloxane bonds at the interfacial layer lowering the bond strength ${ }^{(63)}$. The reason for higher bond stability in alkaline media compared to neutral and acidic media might be attributed to the fact that precipitated alkaline compounds at interface can withstand presence of moisture ${ }^{(64)}$. This was in accordance to Lorenzoni et al ${ }^{(65)}$ who evaluated the effect of an alkaline primer agent on bond strength to zirconia ceramics. They postulated that the increase in the availabilty of hydroxyl groups $(\mathrm{OH})$ after immersion in alkaline medium might have favored delayed acid base reaction between the metal oxides present on the ceramic surface with acidic primer agents and resin composites increasing bond strength.

When observing the results of one step versus two step treatment protocols for different ceramics, VITA SUPRINITY group stored in acidic and alkaline media, showed no statistical significant difference between the two surface treatment protocols in contrast to e.max CAD and VITA ENAMIC groups where the two step treatment showed higher statistical significant difference than one step treatment. This difference could be attributed mainly to presence of noticeably higher percentage zirconia fillers in VITA SUPRINITY compared to e.max CAD and VITA ENAMIC groups ${ }^{(66)}$.The toughness of these zirconia fillers might devalue the effect of surface treatment protocol on microshear bond strength for the VITA SUPRINITY ceramics making them more chemically stable in both acidic and alkaline media.

Limitations of this study are mainly due to its invitro nature where there is absence of salivary washing effect, cyclic loading as well as thermal fluctuations that might influence shear bond strength. However, its objective was clear to investigate the sole effect of different ph solutions on resin ceramic bond strength utilizing 2 surface treatment protocols which gives an informative and more precise conclusion regarding this factor. Further 
investigations are highly recommended to assess long term stability of resin ceramic bond strength under various oral conditions using different ceramics and alternative surface treatments.

\section{CONCLUSIONS}

Within the limitations of this study, the following conclusions and clinical recommendations could be advised:

1) Although microshear bond strength of the two step etch and prime surface treatment protocol was significantly higher than that of one step self-etching ceramic primer protocol,however the values for all tested materials under various $\mathrm{Ph}$ conditions were nearly within a clinically acceptable range, thus it could be suggested that self etching primers can be safely used without affecting clinical performance of the restorations.

2) In patients subjected to predominately acidic or alkaline oral $\mathrm{pH}$ environments, both surface treatment protocols can be safely used when VITA SUPPRINITY restorations are indicated, however when VITA ENAMIC or e.max CAD are used, it is recommended to use the two step surface treatment protocol to ensure more stable bond strength

3) In patients having a neutral balanced oral $\mathrm{pH}$ environment, both surface treatment protocols can be safely used when VITA ENAMIC or e.max CAD restorations are used, however when VITA SUPPRINITY is recommended, it is advisable to use the two step surface treatment protocol to yield better ceramic resin bond durability.

4) Generally speaking, VITA ENAMIC restorations combined with one step self etching primer are not recommended for patients having acidic $\mathrm{pH}$ oral media as it yielded the lowest bond strength values between all subgroups

\section{REFERENCES}

1. Biacchi G, Mello B, Basting R. The endocrown: an alternative approach for restoring extensively damaged molars. J Esthet Restor Dent 2013;25:383-90.

2. Dejak B, Mlotkowski A. Three-dimensional finite element analysis of strength and adhesion of composite resin versus ceramic inlays in molars. J Prosthet Dent 2008;99:131-40.

3. Elsaka S. Bond strength of novel CAD/CAM restorative materials to self-adhesive resin cement: the effect of surface treatments. J Adhes Dent 2014;16:531-40.

4. Borges G, Sophr A, De Goes M, Sobrinho L, Chan D. Effect of etching and airborne particle abrasion on the microstructure of different dental ceramics. J Prosthet Dent 2003;89:479-88.

5. Torres S, Borges G, Spohr A, Cury A, Yadav S, Platt J. The effect of surface treatments on the micro-shear bond strength of a resin luting agent and four all-ceramic systems. Oper Dent 2009;34:399-407.

6. Kalavacharla V, Lawson N, Ramp L, Burgess J. Influence of etching protocol and silane treatment with a universal adhesive on lithium disilicate bond strength. Oper Dent 2014;40:372-8.

7. Duarte S, Sartori N, Phark J-H. Ceramic-reinforced polymers: CAD/CAM hybrid restorative materials. Curr Oral Health Rep 2016;37:32-48.

8. Blatz M, Sadan A, Kern M. Resin-ceramic bonding: a review of the literature. J Prosthet Dent 2003;89:268-74.

9. Tian T, Tsoi J, Matinlinna J, Burrow M. Aspects of bonding between resin luting cements and glass ceramic materials. Dent Mater 2014;30(7):e147-62.

10. Matinlinna J, Lassila L, Özcan M, Yli-Urpo A, Vallittu P. An introduction to silanes and their clinical applications in dentistry. Int J Prosthodont 2004;17:155-64.

11. Kitayama S, Nikaido T, Takahashi R, Zhu L, Ikeda M, Foxton RM, Sadr A, Tagami J. Effect of primer treatment on bonding of resin cements to zirconia ceramic. Dent Mater 2010;26(5):426-32.

12. Meldrum M. Toxicology of hydrogen fluoride in relation to major accident hazards. Regul Toxicol Pharmacol 1999; 30:110-6.

13. Hooshmand T, van Noort R, Keshvad A. Bond durability of the resin-bonded and silane treated ceramic surface. Dent Mater 2002;18:179-88.

14. Klosa K, Boesch I, Kern M. Long-term bond of glass ceramic and resin cement: evaluation of titanium tetrafluoride as an alternative etching agent for lithium disilicate ceramics. J Adhes Dent 2013;15(4):377-83.

15. Chu PK, Chen JY, Wang LP, Huang N. Plasma-surface modification of biomaterials. Mater Sci Eng R 2002; 36:143-206. 
16. Oyague RC, Monticelli F, Toledano M, Osorio E, Ferrari $\mathrm{M}$, Osorio R. Effect of water aging on microtensile bond strength of dualcured resin cements to pre-treated sintered zirconium-oxide ceramics. Dent Mater 2009;25:392-399.

17. Phark J, Duarte S, Blatz M, Sadan A. An in vitro evaluation of the long-term resin bond to a new densely sintered highpurity zirconium-oxide ceramic surface. J Prosthet Dent 2009;101:29-38

18. Amaral R, Ozcan M, Valandro L, Balducci I, Bottino M. Effect of conditioning methods on microtensile bond strength of phosphate monomer-based cement to zirconia ceramic in dry and aged conditions. J Biomed Mater Res Part B Appl Biomater 2008;85B:1-9.

19. Wegner S, Gerdes W, Kern M. Effect of different artificial aging conditions on ceramic-composite bond strength. Int J Prosthodont 2002;15:267-272.

20. Luthy H, Loeffel O, Hammerle C. Effect of thermocycling on bond strength of luting cements to zirconia ceramic. Dent Mater 2006;22:195-200.

21. Silva K, Pedrini D, Delbem A, Cannon M. Effect of $\mathrm{pH}$ variations in a cycling model on the properties of restorative materials. Oper Dent 2007;32:328-335.

22. Anusavice K. Degradability of dental ceramics. Adv Dent Res $1992 ; 6: 82-89$.

23. Milleding $\mathrm{P}$, Wennerberg A, Alaeddin S, Karlsson S, Simon E. Surface corrosion of dental ceramics in vitro. Biomaterials 1999; 20:733-746.

24. Milleding P, Haraldsson C, Karlsson S. Ion leaching from dental ceramics during static in vitro corrosion testing. $\mathrm{J}$ Biomed Mater Res 2002; 61:541-550.

25. Butler C, Masri R, Driscoll C, Thompson G, Runyan D, von Fraunhofer A. Effect of fluoride and $10 \%$ carbamide peroxide on the surface roughness of low-fusing and ultra low-fusing porcelain. J Prosthet Dent 2004;92:179-183.

26. Ccahuana V, Ozcan M, Mesquita A, Nishioka R, Kimpara E, Bottino M. Surface degradation of glass ceramics after exposure to acidulated phosphate fluoride. J Appl Oral Sci 2010;18:155-165.

27. Junpoom P, Kukiattrakoon B, Hengtrakool C. Surface characteristic changes of dental ceramics after cyclic immersion in acidic agents and titratable acidity. Eur $\mathrm{J}$ Prosthodont Restor Dent 2010; 18:177- 184.

28. Kukiattrakoon B, Hengtrakool C, Kedjarune-Leggat U. Degradability of fluorapatite-leucite ceramics in naturally acidic agents. Dent Mater J 2010; 29:502-511.

29. Kukiattrakoon B, Hengtrakool C, Kedjarune-Leggat U. The effect of acidic agents on surface ion leaching and surface characteristics of dental porcelains. J Prosthet Dent 2010;103:148-162.
30. Jain P, Nihill P, Sobkowski J, Agustin M. Commercial soft drinks: $\mathrm{pH}$ and in vitro dissolution of enamel. Gen Dent 2007; 55:150-154.

31. Bartlett D, Fares J, Shirodaria S, Chiu K, Ahmad N, Sherriff $\mathrm{M}$. The association of tooth wear, diet and dietary habits in adults aged 18-30 years old. J Dent 2011;39:811-816.

32. Drummond J, Novickas D, Lenke J. Physiological aging of an all-ceramic restorative material. Dent Mater 1991 ; 7:133-137.

33. Pinto MM, Cesar PF, Rosa V, Yoshimura HN. Influence of $\mathrm{pH}$ on slow crack growth of dental porcelains. Dent Mater 2008 ; 24:814-823.

34. Milleding P, Gerdes S, Holmberg K, Karlsson S. Surface energy of non-corroded and corroded dental ceramic materials before and after contact with salivary proteins. Eur J Oral Sci 1999;107:384-392.

35. Shimada Y, Yamaguchi S, Tagami J. Micro-shear bond strength of dual-cured resin cement to glass ceramics. Dent Mater 2002;18(5):380-388

36. Monobond etch and prime, Ivoclar Vivadent, AG.

37. Addison O, Marquis P, Fleming G. The impact of hydrofluoric acid surface treatments on the performance ofa porcelain laminate restorative material. Dent Mater 2007;23:461-8.

38. Hooshmand T, Parvizi S, Keshvad A. Effect of surface acid etching on the biaxial flexural strength of two hotpressedglass ceramics. J Prosthodont 2008;17:415-9.

39. Zogheib L, Bona A, Kimpara E, McCabe J. Effect of hydrofluoric acid etching duration on the roughness andflexural strength of a lithium disilicate-based glass ceramic.Braz Dent J 2011;22:45-50.

40. Venturini A, Prochnow C, May L, Bottino M, Valandro L.Influence of hydrofluoric acid concentration on the flexuralstrength of a feldspathic ceramic. J Mech Behav Biomed Mater 2015;48:241-8.

41. Ozcan M, Allahbeickaraghi A, Dündar M. Possible hazardous effects of hydrofluoric acid and recommendations for treatment approach: a review. Clin Oral Investig 2012; 16:15-23.

42. Siqueira F, Alessi R, Cardenas A, Kose C, Souza Pinto S, Bandeca M. New single-bottle ceramic primer:6-month case report and laboratory performance. J Contemp Dent Pract 2016;17:1033-9.

43. Román-Rodríguez J, Perez-Barquero J, GonzalezAngulo E, Fons-Font A, Bustos-Salvador J. Bonding to silicateceramics: conventional technique compared with asimplified technique. J Clin Exp Dent 2017;9:e384-6.

44. El-Damanhoury H, Gaintantzopoulou M. Self-etching ceramic primer versus hydrofluoric acid etching: etching 
efficacy and bonding performance. J Prosthodont Res 2018;62:75-83

45. Wille S, Lehmann F, Kern M. Durability of resin bonding to lithium disilicate and zirconia ceramic using a selfetching primer. J Adhes Dent 2017;19:491-6.

46. Geurtsen W, Leyhausen G \& Garcia-Godoy F. Effect of storage media on the fluoride release and surface microhardness of four polyacid-modified composite resins (“compomers”). Dental Materials 1999; 15(3) 196-201.

47. Okada K, Tosaki S, Hirota K \& Hume WR. Surface hardness change of restorative filling materials stored in saliva Dental Materials 2001; 17(1) 34-39.

48. Yehoshuva R, Vamsi P, Sri K, Abhinaya R, Sridhar R, Navnit K.Salivary changes in medically compromised patients: A clinical and biochemical study, Salivary $\mathrm{pH}$ : A diagnostic biomarker. J of Indian Academy of oral medicine and radiology 2017; 29 (1) 12-15

49. Sharmila B, Sangeeta M, and Rahul K. Salivary pH: A diagnostic biomarker).J Indian Soc Periodontol. 2013; 17(4): 461-465.

50. Ardu S, Braut V, Gutemberg D, Krejci I, Dietschi D, Feilzer A. A long-term laboratory test on staining susceptibility of esthetic composite resin materials. Quintessence Int 2010;41:695-702.

51. Arocha MA, Mayoral JR, Lefever D, Mercade M, Basilio J, Roig M. Color stability of siloranes versus methacrylatebased composites after immersion in staining solutions. Clinical Oral Investigations 2013;17:1481-7.

52. Garcia R, do Nascimento R, Gomes A, GarciaJ, Miguel A, Moon P, Fernandes S. Bond strength of resin cements to leucite-reinforced ceramics: part 2 - after one-year aging in water. South brazilian dent j. 2016 ;13(3):156-62

53. Scherrer S, Cesar P, Swain M. Direct comparison of the bond strength results of the different test methods: a critical literature review. Dent Mater 2010;26:e78-93.

54. Andrade A, Garcia E, Moura S, Reis A, Loguercio A, Silva L. Do the microshear test variables affect the bond strength values? Int J Dent 2012;2012:1-6.

55. Thurmond J, Barkmeier W, Wilwerding T. Effect of porcelain surface treatments on bond strengths of composite resin bonded to porcelain.J Prosthet Dent.1994;72(4);355-9

56. Ramakrishnaiah R, Alkheraif A, Divakar D, Matinlinna J, Vallittu P.The effect of hydrofluoric acid etching duration on the surface micromorphology, roughness, and wettability of dental ceramics. Int. J. Mol. Sci.2016; 17, 822-839.
57. Ramakrishnaiah, R., Samer A, Alkheraif A, Darshan D, Elsharawy M, Matinlinna P, Vallittu P. Micro and nano structural analysis of dental ceramic and luting resin interface and the effect of water exposure on integrity of cement interface. J. Biomater. Tiss. Eng. 2018 ;8, 136-143.

58. Della Bona, A., van Noort, R. Shear vs. tensile bond strength of resin composite bonded to ceramic. J. Dent. Res.1995; 74, 1591-1596.

59. Ho G and Matinlinna J. Insights on ceramics as dental materials. Part II: chemical surface treatments. Silicon 2011;3, 117.

60. Asiry M, AlShahrani I, Alaqeel S, Durgesh B, Ramakrishnaiah R,Effect of two-step and one-step surface conditioning of glass ceramic on adhesion strength of orthodontic bracket and effect of thermo-cycling on adhesion strength Journal of the Mechanical Behavior of Biomedical Materials 2018;84, 22-27

61. Scherer M, Prochnow C, Venturini A, Pereira G, Burgo T, Rippe M, Valandro F,Fatigue failure load of an adhesively-cementedlithium disilicate glass-ceramic: Conventionalceramic etching vs etch \& prime one-step primer). Dental materials 2018;34,1134-1143

62. Siqueira F, Alessi R, Cardenas A, Kose C, Pinto S, Bandeca M, Loguercio A, Gomes J.New Single-bottle Ceramic Primer: 6-month Case Report and Laboratory Performance) The Journal of Contemporary Dental Practice 2016;17(12):1033-1039

63. Matinlinna J, Lassila L. Experimental novel silane system in adhesion promotion between dental resin and pretreated titanium. Part II: effect of long term water storage. Silicon 2010;2:79-85.

64. Qian M, Lu Z, Chen C, Zhang H, Xie H. Alkaline nanoparticle coatings improve resin bonding of 10-me thacryloyloxydecyldihydrogenphosphate-conditioned zirconia. International Journal of Nanomedicine 2016:11 5057-5066

65. Lorenzoni F, Leme V, Santos L, de Oliveira P, Martins L, Bonfante G. Evaluation of Chemical Treatment on Zirconia Surface with Two Primer Agents and an Alkaline Solution on Bond Strength. Operative Dentistry; 2012, 37 6, 625-633.

66. VITA SUPPRINITY.VITA Zahnfabrik H. Rauter GmbH \& Co.KG (Scientific documentation 2016). 